\title{
Função docente: natureza e construção do conhecimento profissional ${ }^{*}$
}

\author{
Maria do Céu Roldão \\ Universidade do Minho, Centro de Estudos da Criança
}

\section{Ensinar enquanto especificidade profissional do professor}

A questão prévia que norteia a análise que neste texto se procurará desenvolver é a seguinte: Que é um professor? O que o distingue de outros actores sociais e de outros agentes profissionais? Qual a especificidade da sua acção, o que constitui a sua "distinção?" (Reis Monteiro, 2000). Será a partir da discussão da natureza da função específica do professor que se procurará contribuir para a análise das questões do conhecimento profissional docente, na medida em que estas duas dimensões se configuram como interdependentes.

A questão enunciada, tal como as possíveis tentativas de resposta, não existe per se, como sabemos; trata-se de uma construção histórico-social em permanente evolução. Todavia, em cada tempo e contexto, a consciência da mutabilidade, historicidade e relatividade dos conceitos, papéis e funções sociais e profissionais não impede - antes exige - que, no tempo e no contexto em que se vive, sejamos capazes de

* Foi conservada a ortografia de Portugal. a ler com a clareza possível à luz do conhecimento e dos referentes disponíveis. É nesta perspectiva que se avançam as ideias defendidas neste texto.

Assim, o caracterizador distintivo do docente, relativamente permanente ao longo do tempo, embora contextualizado de diferentes formas, é a aç̧ão de ensinar. Mas coloca-se a este respeito um conjunto de questões, quer históricas quer conceptuais: por um lado, importa saber o que se entende por ensinar, o que está longe de ser consensual ou estático; por outro, o reconhecimento da função não é contemporâneo do reconhecimento e afirmação histórica de um grupo profissional associado a ela. Pelo contrário, a função existiu em muitos formatos e com diversos estatutos ao longo da história, mas a emergência de um grupo profissional estruturado em torno dessa função é característico da modernidade, mais propriamente a partir do século XVIII.

No que respeita à representação do conceito de ensinar, a sua leitura é ainda hoje atravessada por uma tensão profunda (Roldão, 2005c) entre o "professar um saber" e o "fazer outros se apropriarem de um saber" - ou melhor, "fazer aprender alguma coisa a alguém”. No limite, e simplificando, tem-se associa- 
do à primeira leitura a postura mais tradicional do professor transmissivo, referenciado predominantemente a saberes disciplinares, e à segunda uma leitura mais pedagógica e alargada a um campo vasto de saberes, incluindo os disciplinares.

$\mathrm{Na}$ verdade, essa dicotomia, com típicos movimentos pendulares fortemente ideologizados nas práticas das administrações e das escolas e professores, tem sido, na nossa perspectiva, eminentemente redutora. Do nosso ponto de vista, a dialéctica do ensino transmissivo versus o ensino activo faz parte de uma história relevante, mas passada, e remete, na sua origem, para momentos e situações contextuais e sóciohistóricas específicas. À luz do conhecimento mais actual, importa avançar a análise para um plano mais integrador da efectiva complexidade da acção em causa e da sua relação profunda com o estatuto profissional daqueles que ensinam: a função específica de $e n$ sinar já não é hoje definível pela simples passagem do saber, não por razões ideológicas ou apenas por opções pedagógicas, mas por razões sócio-históricas.

O entendimento de ensinar como sinónimo de transmitir um saber deixou de ser socialmente útil e profissionalmente distintivo da função em causa, num tempo de acesso alargado à informação e de estruturação das sociedades em torno do conhecimento enquanto capital global. Num passado mais distante, pelo contrário, essa interpretação de ensinar assumia um significado socialmente pertinente, quando o saber disponível era muito menor, pouco acessível, e o seu domínio limitado a um número restrito de grupos ou indivíduos. Nesses contextos - que, de um modo global, caracterizaram o desenvolvimento da escolaridade até finais da primeira metade do século $\mathrm{XX}$ era socialmente justificada a associação da ideia de ensinar com a de passar conhecimento, de "professar" o saber, de torná-lo público, de "lê-lo" para os outros que o não possuíam.

${ }^{1}$ Veja-se o termo "lente", que se aplicava em Portugal, num passado não muito distante, ao professor catedrático, expoente máximo da posse de um saber, e do conseqüente poder de o distribuir, apresentar, professar.
A função de ensinar, nas sociedades actuais, e retomando uma outra linha de interpretação do conceito, ${ }^{2}$ é antes caracterizada, na nossa perspectiva, pela figura da dupla transitividade e pelo lugar de mediação. Ensinar configura-se assim, nesta leitura, essencialmente como a especialidade de fazer aprender alguma coisa (a que chamamos currículo, seja de que natureza for aquilo que se quer ver aprendido) a $a l$ guém (o acto de ensinar só se actualiza nesta segunda transitividade corporizada no destinatário da acção, sob pena de ser inexistente ou gratuita a alegada acção de ensinar) (Roldão, 2005a).

Tal não significa que nos possamos satisfazer com esta proposição conceptual para analisar o que é ensinar, e muito menos tomar qualquer destas tentativas exploratórias do conceito e da função como definitivas ou definidoras... Avançamo-las, sim, como uma hipótese de trabalho que nos parece potenciadora de alguma clarificação no debate científico sobre a profissionalidade docente. Como Shulman (1986, p. 29) bem sublinhou, "teaching is a beautifully ambiguous term".

A história recente dos professores, na sua constituição gradual como grupo profissional, ou pré ou semiprofissional (Gimeno Sacristán, 1995), desenvolve-se num processo complexo de profissionalização que Nóvoa (1995) organiza num modelo de análise clarificador. ${ }^{3}$ No conjunto de factores complexos cuja relação esse modelo nos permite interpretar, entende-

${ }^{2}$ Este entendimento de ensinar como "conduzir" o outro a aprender remete para as origens do termo pedagogo - etimologicamente, aquele que conduz (ago) a criança (paidos) ao conhecimento e à cultura -, associadas, como sabemos, à prática de ensino cometida a escravos gregos na antiga Roma, tornados educadores dos filhos dos romanos vencedores.

${ }^{3}$ Ver Nóvoa (1995, p. 20). O modelo aí desenvolvido organiza-se em quatro etapas evolutivas e em torno de duas dimensões: (a) corpo de conhecimentos e de técnicas e (b) conjunto de normas e valores, em cujo cruzamento se estabelece como eixo estruturante, em cada momento, o estatuto social e económico dos professores. Ver também Nóvoa (2005), para a dimensão histórica da construção da profissão. 
mos destacar, na perspectiva que aqui adoptamos, a ligação particular desse caminho para a profissionalização do professorado a dois processos sociais, distintos mas complementares:

a) um, extrínseco, de natureza político-organizativa: a institucionalização da escola como organização pública, e do currículo que a legitima no plano social, a partir da necessidade de: (a) alfabetizar a população, incluindo a trabalhadora, no pós-Revolução Industrial; e (b) viabilizar um maior grau de politização das populações, necessário mesmo para os níveis mínimos de participação na vida pública nas sociedades pós-antigo regime; é assim a afirmação social da instituição escola que vai funcionar como alavanca principal, ainda que não única, do processo gradual de afirmação dos docentes como grupo profissional socialmente identificável;

b) outro, de natureza intrínseca, associado à necessidade de legitimar esse grupo social dos docentes pela posse de determinado saber distintivo: a afirmação de um conhecimento profissional específico, corporizado, e, por sua vez, estimulado pelo reconhecimento da necessidade de uma formação própria para o desempenho da função, reconhecimento que constituiu um dos grandes passos, no início do século XX em particular, para o reconhecimento social dos docentes enquanto grupo profissional.

Tal processo de profissionalização não é, contudo, linear nem unidireccional. Como sublinha Nóvoa (1995, p. 21), alternam na história dos professores desde o século XIX períodos de profissionalização e desprofissionalização, pautados por conflitos de interesses e actores: "A afirmação profissional dos professores é um percurso repleto de lutas e de conflitos, de hesitações e de recuos. [...] A compreensão do processo de profissionalização exige, portanto, um olhar atento às tensões que o atravessam".
Vive-se de novo, actualmente, um momento particularmente crítico desse processo de desenvolvimento do grupo profissional, em que se joga, quanto a nós, a afirmação ou esbatimento da profissionalidade docente, por força de factores como a massificação escolar, com a conseqüente expansão e diversificação dos públicos escolares, a imobilidade persistente dos dispositivos organizacionais e curriculares da escola geradora do seu anacronismo ante as realidades actuais, a pressão das administrações e dos poderes económicos para uma funcionarização acrescida dos docentes, todavia também largamente alimentada pelos próprios professores, prisioneiros de uma cultura que se instalou ao longo deste processo e que contradiz a alegada reivindicação - no discurso político e no discurso dos próprios docentes - de uma maior autonomia e decisão, desejavelmente associadas a um reforço de profissionalidade.

Neste quadro de contradições e tensões, partimos do pressuposto da absoluta centralidade do conhecimento profissional, embora enquadrado na teia de todos os outros elementos, como factor decisivo da distinção profissional, na fase do processo de evolução histórica da profissão que se atravessa, claramente marcado pela tensão entre o salto para um nível mais consistente de profissionalidade ou o risco de recuo para situações de proletarização e funcionarização reforçadas (Apple, 1997).

\section{0 lugar do conhecimento na definição da profissionalidade docente, ou da urgência da delimitação de um saber específico}

Todas as profissões que construíram ao longo do tempo o reconhecimento de um estatuto de profissionalidade plena (médicos, engenheiros, arquitectos, entre outros) se reconhecem, se afirmam e são distinguidas, na representação social, pela posse de um saber próprio, distinto e exclusivo do grupo que o partilha, produz e faz circular, conhecimento esse que lhe legitima o exercício da função profissional em causa (Rodrigues, 1997). Por isso insistimos anteriormente na clarificação da função de ensinar: é que 
existe uma estreitíssima ligação entre a natureza da função e o tipo de conhecimento específico que se reconhece como necessário para a exercer.

No caso dos professores, quer a função quer o conhecimento profissional se têm mutuamente contaminado, por um lado, por uma tendência para a difusão envolvida de uma discursividade humanista abrangente, que não permite aprofundar a especificidade da função nem do saber; por outro lado, e no extremo oposto, por uma orientação para a especificação operativa, associada à redução do ensino a acções práticas que se esgotam na sua realização, em que o saber é mínimo e a reflexão dispensável, e que acabam traduzindo-se numa tecnicização da actividade. Nenhuma destas tendências se constitui em produtora credível de desenvolvimento e afirmação profissional.

Por isso afirmámos noutro local ser o conhecimento profissional o "elo mais fraco" da profissão docente (Roldão, 2005a), aquele em que importa investir como alavanca capaz de reverter o descrédito, o desânimo, o escasso reconhecimento - factores repetidamente identificados na investigação sobre professores e desenvolvimento profissional (Roldão, 2005b).

Para discutir o conhecimento profissional docente e analisar o seu peso no desempenho da actividade dos docentes, com implicações evidentes no estado de desenvolvimento ou esbatimento, presente e futuro, da sua profissionalidade, e no sentido de isolar uma vertente dentro da complexidade da problemática, decidimos situar esta análise não nas questões da construção e uso desse conhecimento, ${ }^{4}$ mas a montante, na tentativa de clarificação da sua natureza.

\section{Da natureza do conhecimento profissional docente: o teórico e o prático, ou talvez não...}

As dificuldades na clarificação da especificidade do conhecimento profissional docente resultam de

${ }^{4}$ Da clarificação da natureza do conhecimento profissional docente - articulada com a sua construção e o seu uso - decorrem as principais implicações para as questões da formação. Ver Roldão (2006a). vários factores. Entre esses factores conta-se a própria complexidade da função, como anteriormente se referiu. Outros factores de complexidade ligam-se à inevitável miscigenação de elementos pessoais e profissionais no desempenho docente, agravados com o peso da história e dos multissignificados que ensinar assumiu em contextos tão diversos como o da missionação, ou o do perceptorado, miscigenação essa que dificulta por vezes a clarificação da natureza da acção docente. Tal indefinição, acrescida da influência de correntes teóricas diversas, umas de matriz personalista, ou subsidiárias da não directividade, outras orientadas pelos conceitos do behaviorismo ou da educação eficaz nos seus formatos mais radicais, empurram a função de ensinar ora para a indefinição ora para a tecnicização, na esteira do que Mark Holmes (1991, p. 65) identificava como o efeito do balanço pendular entre uma perspectiva tecnocrática e uma perspectiva terapêutica relacional, ambas, na sua óptica, subversivas da educação.

Outros factores de dificuldade, e de não menos importância, resultam da preexistência histórica da aç̧ão de ensinar ante a formalização da formação para ensinar, que vem a articular os corpos de saber necessários à formação de alguém que ensina. Lourdes Montero (2005, p. 19) sublinha a este propósito a complexidade da "conversão de um campo de prática profissional num campo de conhecimento", conversão que, segundo Honore (1980, p. 18), se configura mediante um processo de reflexão.

A actividade de ensinar - como sucedeu com outras actividades profissionais - praticou-se muito antes de sobre ela se produzir conhecimento sistematizado. Estas profissões transportam por isso uma inevitável "praticidade" que, a não ser questionada/ teorizada, jamais transformaria a actividade em acção profissional e mante-la-ia prisioneira de rotinas não questionadas e incapazes de responder à realidade. Todavia, a progressiva teorização da acção, neste como noutros domínios, foi gerando, por sua vez, novos corpos de conhecimento, que passam a alimentar - e a transformar - a forma de agir dos profissionais em causa. 
Esta anterioridade/interacção da prática ante sua teorização, comum às actividades sociopráticas (De Castell, Luke \& Luke, 1989) como a medicina ou o ensino, carreia toda a complexidade daquilo que o jargão académico invoca como a relação teoria-prática. É aí de facto que se joga grande parte da dificuldade de estabelecer a natureza do conhecimento profissional docente e de configurar os modos e identificar os actores da sua produção e uso. É justamente neste interface teoria-prática que se jogam, julgamos, as grandes questões relativas ao conhecimento profissional docente que hoje estão na agenda da formação e da profissionalização dos professores, questões que adiante nos propomos discutir.

A formalização do conhecimento profissional ligado ao acto de ensinar implica a consideração de uma constelação de saberes de vário tipo, passíveis de diversas formalizações teóricas - científicas, científicodidácticas, pedagógicas (o que ensinar, como ensinar, a quem e de acordo com que finalidades, condições e recursos), que contudo, se jogam num único saber integrador, situado e contextual - como ensinar aqui e agora-, que se configura como "prático".

Importa distinguir, contudo, no uso dos termos teórico e prático, os limites com que aqui os abordamos. Trata-se, em ambos os casos, da possibilidade de uma dupla aproximação, já que podemos nos referir: 1) ao saber teórico produzido e formalizado pela investigação sobre a prática de ensinar, ou 2) ao conhecimento teórico produzido ou mobilizado pelos actores na prática de ensinar (que não exclui a anterior, mas a utiliza noutra sede). Por seu lado, ao referenciar o conhecimento dito "prático", podemos designar: a) o "saber fazer" apenas (resultando num praticismo ou num tecnicismo simplista), ou, pelo contrário, b) o saber fazer, saber como fazer, e saber porque se faz. Em ambos os conceitos, é a segunda opção a que aqui adoptamos e procuraremos discutir. Consideramos que a clássica fórmula relação teoria-prática transporta uma conceptualização simbólica que pode ser pouco operativa, ocultando a íntima dependência de um campo diante do outro. De facto, tal formulação vem sendo apropriada no sentido de uma visão destes dois cam- pos como entidades separadas no seu desenvolvimento, cuja interligação se traduziria apenas em processos de aplicação - da teoria à prática. É essa leitura aplicacionista que se evidencia como dominante entre os docentes, tal como a investigação nos dá conta (Roldão, 2006a). Requer-se assim, julgamos, na situação específica dos saberes sociopráticos, como é o caso do conhecimento específico subjacente à função de ensinar, um esforço de reconceptualização da proclamada relação teoria-prática.

Relativamente à natureza do conhecimento profissional docente, é abundante a teorização produzida, de que Montero (2005) nos oferece uma extensa e profunda análise crítica e posicionamento próprio. Na vasta produção sobre o conhecimento profissional docente, é possível identificar, segundo a autora, duas linhas dominantes, ainda assim admitindo múltiplas versões no seu interior e aproximações entre si: uma linha que se aproxima dos estudos de Lee Shulman $(1986,1987)$ e Shulman e Shulman (2004), que operam sobretudo pela desmontagem analítica dos componentes envolvidos no conhecimento global docente (do conhecimento do currículo ao conhecimento dos alunos, do conhecimento científico ao conhecimento didáctico do conteúdo e ao conhecimento científico-pedagógico); e uma outra que, na linha de Freema Elbaz (1983) e Connelly e Clandinin (1984), da corrente teórica do "pensamento do professor" desenvolvida a partir dos anos oitenta do século XX e, sobretudo, sob a forte influência de Donald Schön e da sua epistemologia da prática (1983, 1987), se centra na construção do conhecimento profissional enquanto processo de elaboração reflexiva a partir da prática do profissional em acção.

Segundo Fenstermarcher (1994, p. 15), o primeiro grupo de teóricos acentuaria mais o carácter normativo do conhecimento profissional docente - procurando estabelecer o que os professores devem saber para ensinar bem, ao passo que os investigadores mais ligados à linha do conhecimento prático privilegiam a vertente descritiva/interpretativa do saber profissional, analisando o conhecimento que manifestam os professores que ensinam bem. Preferimos distinguilos pelo predomínio de uma vertente analítico- 
conceptual nos primeiros, e pela valorização de uma vertente holística e contextual nos segundos. Contudo, a análise mais detalhada indicia inúmeros pontos de contacto entre ambas as teorizações. Note-se que a abordagem de Shulman inclui aproximações claras ao modelo do professor investigador (Stenhouse, 1991) e do prático reflexivo (Schön, 1987), e que o conhecimento resultante da prática não se reporta à legitimação de uma qualquer prática, mas ao conhecimento que resulta da reflexão analítica de professores competentes - reflexão e competência que implicitamente convocam, de forma integrada, as categorias que em Shulman aparecem na forma de componentes.

Não pretendemos simplificar a multiplicidade e a riqueza da investigação produzida a dualidades redutoras. Lourdes Montero sublinha que em ambas as correntes referenciadas existe um ponto comum importantíssimo: são amplamente sustentadas por estudos de caso que fundamentam e iluminam as suas teorizações respectivas, ou seja, alimentam-se, de facto, do conhecimento expresso pelos professores em situação real. Muitos autores procuram produzir sínteses das diversas abordagens teorizadoras do conhecimento profissional docente, entre os quais a própria Montero (2005, p. 218), que sistematiza da forma seguinte o seu conceito de conhecimento profissional:

O conjunto de informações, aptidões e valores que os professores possuem, em conseqüência da sua participação em processos de formação (inicial e em exercício) e da análise da sua experiência prática, uma e outras manifestadas no seu confronto com as exigências da complexidade, incerteza, singularidade e conflito de valores próprios da sua actividade profissional; situações que representam, por sua vez, oportunidades de novos conhecimentos e de crescimento profissional.

\section{Para uma tentativa de clarificação de dispositivos "geradores de especificidade" do conhecimento profissional docente}

Da reflexão anterior pode concluir-se que, no plano da clarificação da natureza do conhecimento profissional docente, se configuram duas tendências interpretativas predominantes: uma centrada na análise das suas componentes, outra centrada na valorização da prática profissional reflectida como sua fonte primeira. Tendências que divergem na matriz de análise, mas convergem na interpretação da práxis e do conhecimento que a sustenta - ainda que uma enfatizando o conhecimento prévio necessário, outra valorizando o conhecimento emergente da prática e da reflexão sobre ela.

Para os propósitos que anteriormente enunciámos, é-nos, julgamos, indispensável retomar ambas: por um lado, a vertente que alguns considerarão analítica e mais normativa porque, no plano epistemológico, nos parece possível e necessário desocultar a natureza desse conhecimento particular que é o conhecimento profissional docente através da desmontagem das suas componentes; por outro lado porque se reconhece a valia da epistemologia da prática enquanto iluminadora da sustentação nuclear do conhecimento profissional na reflexão antes, sobre, na e após a acção.

Mas, para além da questão das fontes e dos modos de construção e desenvolvimento do conhecimento profissional que neste texto não incluímos, ao tentar clarificar a natureza desse conhecimento detemo-nos preferencialmente sobre aqueles aspectos que, na nossa perspectiva, são os geradores de especificidade, e que funcionam como agregadores dos outros elementos já teorizados e que antes brevemente recordámos.

A questão que nos move situa-se na compreensão do que há de específico e distintivo neste conhecimento profissional que "deve" (dimensão normativa) caracterizar o conhecimento profissional que, por sua vez, é o conhecimento que subjaz, com mais ou menos articulação, ao que os bons professores fazem e como o fazem (dimensão descritiva). Aparentemente, já quase tudo terá sido dito sobre aquilo que o constitui ou sobre a sua construção no desenvolvimento da prática profissional. Contudo, e se comparamos com o saber definidor de outras profissões, talvez não nos baste o jogo lógico da dimensão analítica e da dimensão narrativa e contextual-reflexiva. Onde se joga afi- 
nal a especificidade desse conhecimento que permite exercer fundamentadamente a função de ensinar?

Em forma tentativa, e tendo em conta que esta análise tem implicações para os processos de formação inicial e contínua, e respectiva sustentabilidade, propomos um conjunto de caracterizadores que concebemos como agregadores e factores de distinção do conhecimento profissional docente. Decorrem simultaneamente de uma lógica normativa - explicitar o "saber ideal" ante a função de ensinar e sua eficácia - e de uma lógica interpretativa da prática real - na medida em que se apoiam em investigação sobre práticas docentes e experiências de formação (Roldão, 2006a).

1. Um primeiro aspecto do conhecimento profissional docente que o distingue é a sua natureza compósita, que é diferente de composta. Não se trata de um conhecimento constituído de várias valências combinadas por lógicas aditivas, mas sim por lógicas conceptualmente incorporadoras - o que também se distingue da ideia de simples integração. Nas práticas de qualidade, verificamos que não basta que se integrem os conhecimentos de várias naturezas, mas que eles se transformem, passando a constituirse como parte integrante uns dos outros. Por exemplo, o conhecimento didáctico de conteúdo incluirá, modificando-o, o conhecimento de conteúdo. Não basta ao professor conhecer, por exemplo, as teorias pedagógicas ou didácticas e aplicá-las a um dado conteúdo da aprendizagem, para que daí decorra a articulação desses dois elementos na situação concreta de ensino. Há que ser capaz de transformar conteúdo científico e conteúdos pedagógico-didácticos numa acção transformativa, informada por saber agregador, ante uma situação de ensino “ por apropriação mútua dos tipos de conhecimento envolvidos, e não apenas por adição ou mera aplicação. Ou seja, um elemento central do conhecimento profissional docente é a capacidade de mútua incorporação, coerente e transformadora, de um conjunto de componentes de conhecimento (tomando as categorias shulmianas como referente dessas componentes). Esta capacidade de agregação implica necessariamente que cada uma dessas componentes tenha sido pre- viamente apropriada com profundidade, mas vai para além dessa apropriação prévia, num processo de conhecimento transformativo.

2. Outro elemento que consideramos, nesta proposta de análise, "gerador de especificidade" do conhecimento profissional, é a capacidade analítica, aspecto que a linha da prática reflexiva vem também acentuando. Tal exercício permanente da capacidade analítica opõe-se directamente ao agir docente rotineiro, ainda que este possa assentar em conhecimento técnico ou mesmo artístico, tantas vezes convocados para legitimar o saber docente no quotidiano. Não é a perícia técnica da aula, tampouco a pura inspiração criativa, que fazem a especificidade do saber docente. E, contudo, o conhecimento profissional (do professor, do médico, entre outros) exige sem dúvida o rigoroso domínio de muito saber técnico (como fazer) e o domínio de uma componente improvisativa e criadora ante o "caso", a "situação", que podemos chamar de "artística". Mas só se converte em conhecimento profissional quando, e se, sobre tais valências (técnica e criativa) se exerce o poder conceptualizador de uma análise sustentada em conhecimentos formalizados e/ou experienciais, que permite dar e identificar sentidos, rentabilizar ou ampliar potencialidades de acção diante da situação com que o profissional se confronta.

3. Um outro elemento que consideramos "gerador de especificidade" do conhecimento profissional docente é a sua natureza mobilizadora e interrogati$v a$ - freqüentemente ausente da cultura e das práticas dos professores, com conseqüências no respectivo sucesso do seu ensino. Em todo o processo de ensinar ${ }^{5}$ se joga constantemente a componente da mobilização - das componentes categoriais de Shulman, aqui tomadas como referente possível, de situações vividas, de semelhanças e diferenças com outros casos/

\footnotetext{
${ }_{5}^{5}$ Adopto como significado de ensinar promover intencio-
} nalmente a aprendizagem de alguma coisa por outros. Ver Roldão (2005a). 
situações observadas. Mobilizar implica convocar inteligentemente, articulando elementos de natureza diversa num todo complexo. De igual modo, e em paralelo com a mobilização, o conhecimento profissional docente, pela singularidade e imprevisibilidade das situações e das pessoas, requer o questionamento permanente, quer da acção prática (mas não só dela, como induzem algumas leituras do senso comum diante do paradigma reflexivo), quer do conhecimento declarativo previamente adquirido, quer da experiência anterior. Como na construção do conhecimento científico formal, também aqui estas duas valências se configuram como essenciais ao desenvolvimento bemsucedido de uma acção socioprática tão complexa como ensinar.

4. Outro "gerador de especificidade" do conhecimento profissional docente, relacionado com a capacidade de questionamento, é a meta-análise, requerendo postura de distanciamento e autocrítica, implícita nos pressupostos de uma prática reflexiva, mas que, sublinha-se, não pode prescindir dos contributos dos vários tipos do conhecimento formal que constituem o saber docente, do conteudinal ao pedagógico-didáctico.

5. Finalmente, a construção de um conhecimento profissional docente implica um outro "gerador de especificidade": comunicabilidade e circulação. Será talvez esta a dimensão que mais afasta, na realidade dominante das práticas actuais de ensino, os docentes da posse de um conhecimento profissional pleno, na medida em que a acentuação da representação da vertente prática do conhecimento docente tem sublinhado as componentes tácitas de conhecimento que de facto a integram. Mas sobre esse conhecimento tácito importa saber exercer, pela meta-análise referida, a desconstrução, desocultação e articulação necessárias à sua passagem a saber articulado e sistemático, passível de comunicação, transmissão, discussão na comunidade de pares e perante outros - sem o que o seu desenvolvimento resulta impossível ou diminuto, perdendo-se infindáveis energias e progressos relevantes do conhecimento produzido pelos docentes, por força desta limitação, muito forte na classe, e expli- cável entre outros factores, pelo praticismo que historicamente se associou à representação social do professor.

\section{Relação teoria-prática? 0 u o saber profissional como a teorização da prática?}

Não nos parece, pois, muito produtiva a eterna discussão acerca do peso relativo da teoria e da prática no exercício da função de ensinar - e na respectiva formação. Na perspectiva em que nos colocamos neste texto, a função de ensinar é socioprática sem dúvida, mas o saber que requer é intrinsecamente teorizador, compósito e interpretativo. Por isso mesmo, o saber profissional tem de ser construído - e refiro-me à formação - assente no princípio da teorização, prévia e posterior, tutorizada e discutida, da acção profissional docente, sua e observada noutros.

Prefiro, assim, em vez de prática docente, falar da acção de ensinar, enquanto acção inteligente, fundada num domínio seguro de um saber. Esse saber emerge dos vários saberes formais e do saber experiencial, que uns e outro se aprofundam e questionam. Torna-se saber profissional docente quando e se o professor o recria mediante um processo mobilizador e transformativo em cada acto pedagógico, contextual, prático e singular. Nessa singularidade de cada situação o profissional tem de saber mobilizar todo o tipo de saber prévio que possui, transformando-o em fundamento do agir informado, que é o acto de ensinar enquanto construção de um processo de aprendizagem de outros e por outros - e, nesse sentido, arte e técnica, mas fundada em ciência.

Dominar esse saber, que integra e mobiliza, operando a convergência que permite ajustá-lo a cada situação, é sim alguma coisa de específico, que se afasta do mero domínio dos conteúdos como da simples acção relacional e interpessoal (Roldão, 2006b). O professor profissional - como o médico ou o engenheiro nos seus campos específicos - é aquele que ensina não apenas porque sabe, mas porque sabe ensinar. E saber ensinar é ser especialista dessa complexa capacidade de mediar e transformar o saber 
conteudinal curricular (isto é, que se pretende ver adquirido, nas suas múltiplas variantes) - seja qual for a sua natureza ou nível ${ }^{6}$ - pela incorporação dos processos de aceder a, e usar o conhecimento, pelo ajuste ao conhecimento do sujeito e do seu contexto, para adequar-lhe os procedimentos, de modo que a alquimia da apropriação ocorra no aprendente - processo mediado por um sólido saber científico em todos os campos envolvidos e um domínio técnico-didáctico rigoroso do professor, informado por uma contínua postura meta-analítica, de questionamento intelectual da sua acção, de interpretação permanente e realimentação contínua. Aprende-se e exerce-se na prática, mas numa prática informada, alimentada por velho e novo conhecimento formal, investigada e discutida com os pares e com os supervisores - ou, desejavelmente, tudo isto numa prática colectiva de mútua supervisão e construção de saber inter pares (Roldão, 2005c).

Saber produzir essa mediação não é um dom, embora alguns o tenham; não é uma técnica, embora requeira uma excelente operacionalização técnico-estratégica; não é uma vocação, embora alguns a possam sentir. É ser um profissional de ensino, legitimado por um conhecimento específico exigente e complexo, de que procurámos clarificar algumas dimensões.

Defendo, com Ivor Goodson (1999), a afirmação do investigador educacional como um "intelectual público" e julgo legítimo estender essa condição ao profissional de ensino, capaz de investigar e teorizar a sua acção docente. Nem por isso menos "prático", porque é de acção e interacção que se trata no ensino - mas acção assente num poderoso conhecimento em constante actualização. A ênfase praticista, que tem dominado a cultura profissional dos professores, não contribui, a meu ver, para o crescimento desta profissão, tanto mais necessária quanto o mundo actual, dito sociedade da informação, está longe de ser um mundo do conhecimento, e muito menos de

${ }^{6}$ Recordo a conhecida afirmação de Jerome Bruner, em 1960, de que é possível ensinar seja o que for em qualquer idade desde que se utilizem processos intelectualmente honestos. conhecimento para todos. Que a informação se torne conhecimento e que o conhecimento seja algo democraticamente acessível, num mundo em que conhecer é poder, depende em larga medida deste novo salto na profissionalização dos professores: a afirmação e o reforço de um saber profissional mais analítico, consistente e em permanente actualização, claro na sua especificidade, e sólido nos seus fundamentos.

\section{Referências bibliográficas}

APPLE, Michael. Os professores e o currículo: abordagens sociológicas. Lisboa: Educa, 1997.

BRUNER, Jerome. The process of education. Cambridge: Harvard University Press, 1960.

CONNELLY, F. Michael; CLANDININ, D. Jean. Personal practical knowledge at Bay Street school. In: HALKES, Rob; OLSON, John K. (Eds.). Teacher thinking: a new perspective on persisting problems in education. Lisse: Swets \& Zeitlinger, 1984. p. 134-148.

DE CASTELL, Suzanne; LUKE, Alan; LUKE, Carmen (Eds). Language, authority and criticism: readings on the school textbook. London: Falmer Press, 1989.

ELBAZ, Freema. Teacher thinking. A study of practical knowledge. Londres: Croom Helm, 1983.

FENSTERMARCHER, Gary. The knower and the known: the nature of knowledge in research on teaching. Review of Research in Education, n. 20, p. 3-56, 1994.

GIMENO SACRISTÁN, José. Consciência e acção sobre a prática como libertação profissional dos professores. In: NÓVOA, António (Org.). Profissão professor. Porto: Porto Editora, 1995. p. 63-92.

GOODSON, Ivor. The educational researcher as a public intellectual. British Educational Research Journal, v. 25, n. 3, p. 277-297, 1999.

HOLMES, Mark. Bringing about change in teachers: rationalistic technology and therapeutic human relations in the subversion of education. Curriculum Inquiry, v. 21, n. 1, p. 65-90, 1991.

HONORE, Bernard. Para una teoria de la formacion. Madrid: Narcea, 1980.

MONTERO, Lourdes. A construção do conhecimento profissional docente. Trad. Armando P. Silva. Lisboa: Instituto Piaget, 2005. NÓVOA, António (Org.). Profissão professor. 2. ed. Porto: Porto Editora, 1995. 
E vid ente mente: histórias da educação. Porto: Edições Asa, 2005.

REIS MONTEIRO, Agostinho. Ser professor. Inovação, v. 3, n. 2-3, p. 11-37, 2000.

RODRIGUES, Maria de Lourdes. Sociologia das profissões. Oeiras: Celta, 1997.

ROLDÃO, Maria do Céu. Formação de professores, construção do saber profissional e cultura da profissionalização: que triangulação? In: ALONSO, Luísa; ROLDÃO, M. Céu (Orgs.). Ser professor de $1^{o}$ ciclo - construindo a profissão. Braga: CESC/ Almedina, 2005a. p. 13-26.

. Formar para a excelência profissional - pressupos-

tos e rupturas nos níveis iniciais da docência. In: SIMPÓSIO NACIONAL DE EDUCAÇÃO BÁSICA: PRÉ-ESCOLAR E $1^{\circ}$ CICLO - FORMAÇÃO DE PROFESSORES E EDUCADORES DE INFÂNCIA: QUESTÕES DO PRESENTE E PERSPECTIVAS FUTURAS, 1., 2003, Aveiro. Anais... Aveiro: Universidade de Aveiro, 2005b. 1 CD-ROM.

Profissionalidade docente em análise - especificidades dos ensinos superior e não superior. Revista NUANCES, Universidade do Estado de São Paulo, ano XI, n. 13, p. 108-126, jan./dez. 2005c.

. A formação de professores como objecto de pesquisa: contributos para a construção do campo de estudo a partir de pesquisas portuguesas. Revista Eletrônica de Educação, Universidade Federal de São Carlos, 2006a. Disponível em: <www.portaldosprofessores.ufscar.br>. Acesso em:jan./jun. 2007.

. Currículo e natureza profissional do conhecimento dos professores: focagem ou difusão? In: COLÓQUIO SOBRE QUESTÕES CURRICULARES, 7./ COLÓQUIO LUSO-BRASILEIRO SOBRE QUESTÕES CURRICULARES, 3., 2006, Braga. Actas... Braga: s.ed., 2006b.

SCHÖN, Donald. The reflective practitioner: how professionals think in action. London: Temple Smith, 1983.

Educating the reflective practitioner. New York: Jossey-Bass, 1987.

SHULMAN, Lee. Those who understand: knowledge growth in teaching. Educational Researcher, v. 15, n. 2, p. 4-14, 1986.
Knowledge and teaching: foundations of the new reform. Harvard Educational Review, n. 57, p. 4-14, 1987.

SHULMAN, Lee; SHULMAN, Judith. How and what teachers learn: a shifting perspective. Journal of Curriculum Studies, v. 36, n. 2, p. 257-271, mar./apr. 2004.

STENHOUSE, Lawrence. Investigación y desarrollo del currículo. 3. ed. Madrid: Morata, 1991.

MARIA DO CÉU ROLDÃO, doutora em teoria curricular pela Simon Fraser University, do Canadá, e agregada em educação pela Universidade de Aveiro, Portugal, é professora coordenadora aposentada da Escola Superior de Educação de Santarém, e investigadora do Centro de Estudos da Criança (CESC) da Universidade do Minho (Portugal). As suas actividades docente e de pesquisa centram-se nas áreas do currículo e da formação de professores. Publicou diversos livros nestes dois domínios entre os quais: Diferenciação curricular revisitada - conceito, discurso e práticas (Porto: Porto Editora, 2003), e numerosos artigos, alguns no Brasil, como é o caso de Profissionalidade docente em análise - especificidades dos ensinos superior e não superior (Revista NUANCES, Universidade do Estado de São Paulo, ano XI, n. 13, p. 108-126, jan./dez. 2005). Organizou diversos livros sobre currículo e educação, entre os quais, em parceria com Luisa Alonso, Ser professor de $1^{\circ}$ ciclo - construindo a profissão (Braga: CESC/ Almedina, 2005). Desenvolve neste momento, no âmbito de uma equipe de pesquisa que co-coordena na Universidade do Minho, o projecto "Prática Pedagógica e Construção do Conhecimento Profissional". O texto agora publicado resultou do seu trabalho de colaboração com a Associação Nacional de Pós-Graduação e Pesquisa em Educação (ANPEd), por iniciativa do Grupo de Trabalho Formação de Professores (GT 8), tendo resultado de comunicação apresentada na $29^{a}$ Reunião Anual realizada em outubro de 2006. E-mail: maria.roldao@netvisao.pt

Recebido em outubro de 2006 Aprovado em dezembro de 2006 


\section{Resumos/Abstracts/Resumens}

Maria do Céu Roldão

\section{Função docente: natureza e construção do conhecimento profissional}

Analisa-se a especificidade da função de ensinar enquanto caracterizadora da actividade do professor e examina-se a evolução e pluralidade de sentidos associados ao conceito de ensinar e suas implicações no desenvolvimento profissional dos docentes ao longo da evolução histórica da actividade. Em um segundo momento, analisa-se também a natureza do conhecimento específico necessário ao desempenho da função de ensinar, procurando dar conta das teorizações existentes acerca desse conhecimento, e propondo e discutindo um conjunto de caracterizadores distintivos desse saber que a autora designa como geradores de especificidade. A proposta do trabalho situa-se no quadro de uma valorização da dimensão analítica e teorizadora da acção de ensinar por parte do professor, no sentido de desenvolvimentos futuros da docência que possam reforçar a afirmação social da profissionalidade dos docentes.

Palavras-chave: função docente; formação profissional

\section{Teacher's role: nature and construction} of professional knowledge

In this paper, the specificity of teaching as a social function is under analysis. The author examines the evolution of the very concept of teaching and the plurality of possible meanings that have been associated with it, as well as their implications in teachers professional development as a group throughout its historic evolution.The nature of the specific knowledge required to teach will be also discussed, supported by existing theorizations on teaching professional knowledge. A set of distinctive descriptors of such knowledge is proposed and discussed. The whole perspective of this discussion is based on the reinforcement and valuing of the dimension of analysis and theorization of teaching activity by teachers themselves, assumed as enhancing the development of the social recognition of teachers as professionals.

Key words: teaching function; teaching professional knowledge

Función docente: naturaleza y construcción del conocimiento profesional

Se analiza la especificidad de la función de enseñar en cuanto caracterizadora de la actividad del profesor y se examina la evolución y la pluralidad de sentidos asociados al concepto de enseñar y sus implicaciones en el desenvolvimiento profesional de los docentes a lo largo de la evolución histórica de la actividad. En un segundo momento, se analiza también la naturaleza del conocimiento específico necesario al desempeño de la función de enseñar, procurando dar cuenta de las teorizaciones que existen a respecto de ese conocimiento, proponiendo y discutiendo un conjunto de caracterizadores distintivos de ese saber que la autora designa como 
generadores de especificidad. La propuesta del trabajo se sitúa en el cuadro de una valorización de la dimensión analítica y teorizadora de la acción de enseñar por parte del profesor, en el sentido de desenvolvimientos futuros de la docencia que puedan reforzar la afirmación social de la profesionalidad de los docentes.

Palabras claves: función docente; conocimiento profesional 